\title{
ANALISIS PENGARUH HARMONISA PADA TRANSFORMATOR DISTRIBUSI DI HARI KERJA DAN HARI LIBUR PADA GEDUNG PERKANTORAN
}

\author{
Muhammad Sultan Reza1, Chairul Hudaya ${ }^{1,2^{\star}}$ \\ ${ }^{1}$ Departemen Teknik Elektro, Fakultas Teknik Universitas \\ Indonesia Kampus Baru UI Depok 16424 Indonesia \\ ${ }^{2}$ Program Studi Magister Manajemen Inovasi, Sekolah Pascasarjana Universitas Teknologi \\ Sumbawa JI. Olat Maras Raya, Batu Alang, Moyo Hulu, Sumbawa, NTB, Indonesia \\ ${ }^{*}$ Corresponding Author email: c.hudaya@uts.ac.id
}

\begin{tabular}{|c|c|}
\hline & Abstrak \\
\hline $\begin{array}{l}\text { Diterima: } \\
\text { Bulan Januari } \\
2021\end{array}$ & $\begin{array}{l}\text { Harmonisa merupakan salah satu fenomena penyimpangan bentuk gelombang tegangan } \\
\text { dan arus yang ditransimisikan dan didistribusikan dari sumber ke beban yang berupa } \\
\text { gelombang sinusoidal murni. Penelitian ini bertujuan untuk mempelajari tentang } \\
\text { pengaruh harmonisa pada transformator distribusi di gedung perkantoran serta }\end{array}$ \\
\hline $\begin{array}{l}\text { Diterbitkan: } \\
\text { Bulan Februari } \\
2021\end{array}$ & $\begin{array}{l}\text { membandingkan pengaruh tersebut di hari kerja dan hari libur. Dari hasil pengukuran di } \\
\text { Sudirman Central Business District diketahui bahwa pada transformator } 1 \text { dan } 3 \text { terdapat } \\
\text { harmonisa dengan persentase THD arus sebesar } 25.27 \% \text { dan } 22.32 \% \text { pada hari kerja } \\
\text { Sementara pada hari libur terdapat transformator } 1 \text { yang mempunyai persentase THD arus }\end{array}$ \\
\hline $\begin{array}{l}\text { Keyword : } \\
\text { Beban non linier, } \\
\text { Harmonisa, } \\
\text { Transformator } \\
\text { Distribusi }\end{array}$ & $\begin{array}{l}\text { sebesar } 17.24 \% \text { yang melebihi batas IEEE } 519-1992 \text { yang diizinkan yaitu } 15 \% \text {. } \\
\text { Harmonisa yang dominan yaitu harmonisa ke-3, ke-5, dan ke-7. Dengan persentase THD } \\
\text { arus yang melebihi batas standar akan mengakibatkan penurunan kinerja dan bahkan } \\
\text { kerusakan alat atau komponen listrik. Hasil dari studi menunjukkan bahwa pada saat } \\
\text { beban kecil (hari libur) THD arus yang dihasilkan tidak terlalu besar dikarenakan beban } \\
\text { non linier yang lebih sedikit digunakan daripada pada saat beban besar (hari kerja). }\end{array}$ \\
\hline
\end{tabular}

\section{PENDAHULUAN}

Sebagian besar peralatan listrik saat ini banyak yang terdapat komponen elektronik. Termasuk peralatan listrik yang digunakan pada gedung perkantoran, seperti air conditioner, printer, Lampu Hemat Energi (LHE) dan lain sebagainya. Peralatan-peralatan seperti ini dapat menimbulkan arus-arus dan tegangan-tegangan terdistorsi yang disebut sebagai harmonisa dimana frekuensi arus dan tegangannya berturut-turut adalah kelipatan dari arus dan tegangan yang dibangkitkan oleh sumber listrik. Distorsi harmonisa disebabkan oleh beban non linier. Harmonisa dapat menyebabkan faktor daya yang semakin buruk, menimbulkan gangguan pada sistem telekomunikasi, dan menimbulkan berbagai macam kerusakan pada peralatan listrik yang sensitif (Geduldt, 2005).

Transformator yang dirancang untuk bekerja pada frekuensi ratingnya dapat berakibat timbulnya rugi dan bertambahnya temperatur yang tidak normal yang dapat mengurangi masa guna transformator akibat pembebanan nonlinier. Kandungan harmonisa yang besar menimbulkan pemanasan berlebih walaupun beban belum mencapai beban nominal. Pemanasan berlebih ini disebabkan oleh meningkatnya rugi-rugi pada transformator yaitu rugi berbeban, rugi $\mathrm{I} 2 \mathrm{R}$, rugi eddy current, serta rugi sasar lainnya (stray losses.

Konsep derating atau penurunan kapasitas daya transformator dibutuhkan untuk mengurangi pengaruh harmonisa pada transformator agar transformator mempunyai masa pakai yang panjang sehingga secara ekonomi menguntungkan dan sekaligus menjaga kehandalan sistem tenaga listrik. Standar IEEE 519-1992 berkaitan dengan konsep ini. Apabila tingkat THDi maupun THDv dibawah $5 \%$ tidak terjadi pemanasan berlebih pada trasnformator yang mana tidak perlu dilakukan penurunan kapasitas daya trasnformator. Begitupula sebaliknya apabila melebihi standar tersebut maka perlu dilakukan penurunan kapasitas transformator.

Oleh karena buruknya dampak harmonisa pada transformator, penulis memiliki tujuan untuk mengetahui seberapa besar rugi daya dan penurunan kapasitas transformator distribusi di gedung perkantoran dimana besar harmonisa diwakilkan dalam bentuk THD (\%) (Total Harmonic Distortion).

\section{LANDASAN TEORI}

\section{Pengertian Harmonisa}

Pada sistem tenaga listrik dirancang agar beroperasi pada frekuensi $50 \mathrm{~Hz}$ atau $60 \mathrm{~Hz}$. Akan tetapi dalam kenyataannya, terdapat beberapabeban yang menyebabkan munculnya arus dan tegangan yang frekuensinya merupakan kelipatan 50 atau 60 Hz. Beban tersebut dinamakan sebagai beban non linier. Sedangkan frekuensi 50 atau $60 \mathrm{~Hz}$ disebut sebagai frekuensi fundamental dan kelipatannya disebut harmonisa atau harmonisa. Harmonisa adalah distorsi periodik dari gelombang sinus arus, 
tegangan, atau daya dengan bentuk gelombang yang frekuensinya merupakan kelipatan diluar bilangan satu terhadap frekuensi fundamental yang mana pada sistem suplai dirancang beroperasi pada 50 Hz/60 Hz (Tobing, 2008).

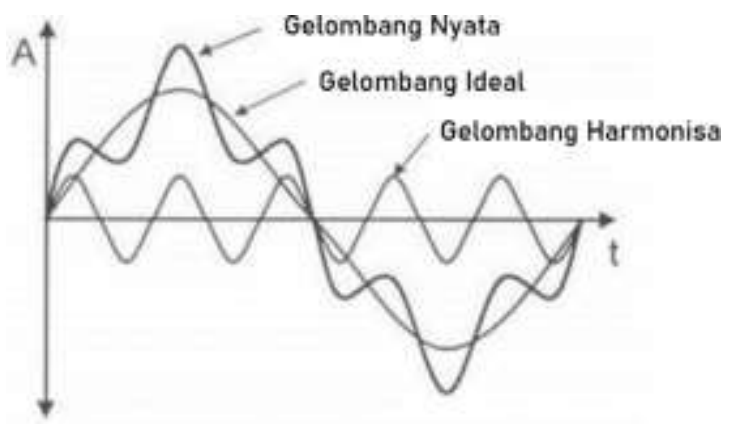

Gambar 2. 1 Gelombang Harmonisa

Keberadaan harmonisa ini membawa kerugian pada beberapa alat, salah satunya adalah tranformator daya. Akibat dari banyaknya persentase kandungan harmonisa akan berakibat pada semakin buruknya kualitas sumber daya listrik. Umumnya arus sistem distribusi tenaga listrik yang terdistorsi tersebut didominasi oleh arus harmonisa orde ganjil frekuensi rendah, yakni arus harmonisa orde tiga, lima, tujuh, sebelas, dan seterusnya. Harmonisa adalah gangguan yang terjadi dalam sistem distribusi tenaga listrik yang disebabkan adanya distorsi gelombang arus dan tegangan. Distorsi gelombang arus dan tegangan ini disebabkan adanya pembentukan gelombanggelombang dengan frekuensi kelipatan bulat dari frekuensi fundamentalnya. Hal ini disebut frekuensi harmonisa yang timbul pada bentuk gelombang aslinya sedangkan bilangan bulat pengali frekuensi dasar disebut angka urutan harmonisa. Jika f adalah frekuensi fundamental dari suatu sistem, maka frekuensi orde $n(1,2,3, \ldots, n)$ adalah nf yaitu $50 \mathrm{~Hz}$, $100 \mathrm{~Hz}, \quad 150 \mathrm{~Hz}$ dan seterusnya Gelombanggelombang ini kemudian menumpang pada gelombang murni / aslinya sehingga terbentuk gelombang cacat yang merupakan jumlah antara gelombang murni sesaat dengan gelombang harmonisanya. Harmonisa urutan genap biasanya memiliki rms yang lebih kecil dibandingkan harmoik urutan ganjil (J. Arrilaga, 2003).

\section{Proses Terjadinya Harmonisa}

Pada tahun 1916 fenomena harmonisa pada sistem tenaga listrik pertama kali diteliti oleh Steinmetz. Ia memberi perhatian pada harmonisa ke3 yang muncul pada sistem tiga fasa. Kemunculan harmonisa ke-3 tersebut disebabkan oleh kejenuhan inti besi pada trafo dan mesin-mesin listrik. Sekitar tahun 1930-1940, masalah harmonisa ke-3 ini dapat teratasi dengan baik. Pada era sekarang ini penyebab munculnya harmonisa sebagian besar adalah alatalat elektronika daya.
Rangkaian elektronika daya digunakan secara luas pada switching power supplies, UPS, komputer, printer, lampu flourescent dan peralatanperalatan lainnya. Elektronika daya digunakan oleh banyak pihak karena efisien dan mudah dikendalikan, akan tetapi perangkat ini dapat menarik arus AC non sinusoidal dari sumber AC. Bila arus ini bereaksi dengan impedansi sitem maka akan membangkitkan tegangan dan/atau arus harmonisa. Gelombang tegangan dan/atau arus harmonisa ini bergerak seolah-olah melawan arah datangnya gelombang tegangan dan/atau arus yang berasal dari sumber. Jika gelombang harmonisa ini bergabung dengan gelombang fundamentalnya, maka gelombang fundamental tersebut akan mengalami distorsi dan mengubah bentuknya menjadi gelombang sinusoidal yang tidak sempurna atau disebut gelombang yang cacat.

Tidak seperti fenomena transien yang akan hilang dalam beberapa mikro detik atau fenomena tegangan DIP yang akan hilang dalam beberapa mili detik, harmonisa merupakan kejadian yang berlangsung secara periodik dan berbentuk steady state. Keberadaan harmonisa secara terus-menerus akan menyebabkan distorsi pada gelombang sinus tegangan dan/atau arus dan hal ini mempunyai beberapa pengaruh buruk terhadap sistem maupun peralatan listrik.

Harmonisa dapat mempengaruhi setiap komponen pada sistem distribusi walaupun dengan akibat yang berbeda. Namun demikian komponen tersebut akan mengalami penurunan kinerja dan bahkan akan mengalami kerusakan. Salah satu dampak yang umum dari gangguan harmonisa adalah panas lebih pada kawat netral dan transformator sebagai akibat timbulnya harmonisa ketiga yang dibangkitkan oleh peralatan listrik satu fasa (Grady, 2002).

\section{Indeks Harmonisa}

a. Root Mean Square

RMS dapat didefinisiakan sebagai akar kuadrat rata-rata dari fungsi yang terdapat amplitudo dari fungsi berkalanya pada suatu periode, sehingga RMS dapat diartikan sebagai persamaan berikut:

$X_{r m s}=\sqrt{\frac{1}{\tau} \int_{0}^{T} x^{2}(t) d t}$

sedangkan untuk menghitung tegangan dan arus (Vrms dan Irms) adalah :

$$
\begin{aligned}
& V_{r m s}=\sqrt{\frac{1}{\tau} \int_{0}^{T} V^{2}(t) d t}=\sqrt{\sum_{n=1}^{\infty} V_{n^{2}}} \\
& I_{r m s}=\sqrt{\frac{1}{T} \int_{0}^{T} I^{2}(t) d t}=\sqrt{\sum_{n=1}^{\infty} I_{n^{2}}}
\end{aligned}
$$

atau dapat juga didefinisikan dengan persamaan berikut:

$$
\begin{aligned}
& I_{r m s}=\sqrt{I_{1^{2}}+I_{2^{2}}+I_{3^{2}}+\cdots+I_{n^{2}}} \\
& V_{r m s}=\sqrt{V_{1^{2}}+V_{2^{2}}+V_{3^{2}}+\cdots+V_{n^{2}}}
\end{aligned}
$$


Nilai RMS merupakan besaran nilai yang sering dipakai dalam kehidupan seharihari. Hal ini berdasarkan kenyataan bahwa pada umumnya alat ukur yang digunakan dalam proses pengukuran besaran listrik biasanya menunjukkan nilai RMS seperti arus rms atau tegangan rms. Nilai RMS digunakan karena beberapa alat elektronik (seperti beberapa komponen pada alat ukur) mempunyai batas untuk menahan kalor/panas tertentu (Indra, 2010).

Di samping itu, berbeda dengan sinyal DC yang memiliki nilai aktual tetap, sinyal AC memiliki nilai aktual yang berubah-ubah secara periodik sehingga pengukuran sinyal $\mathrm{AC}$ dilakukan dengan mencari nilai ekivalen DCnya. Nilai inilah yang disebut dengan nilai RMS yang dalam terminologi elektrik, nilai RMS akan ekuivalen dengan DC heating value-nya. Dengan demikian nilai RMS arus bolak-balik dapat dikatakan sebagai besarnya nilai arus searah yang akan memberikan efek pemanasan yang sama dengan efek pemanasan yang disebabkan arus bolak-balik tersebut pada suatu tahanan yang sama.

Karena pada sistem arus bolak-balik (AC) bentuk gelombang arus maupun tegangan berupa sinusoidal, maka perhitungan RMS adalah sebagai berikut:

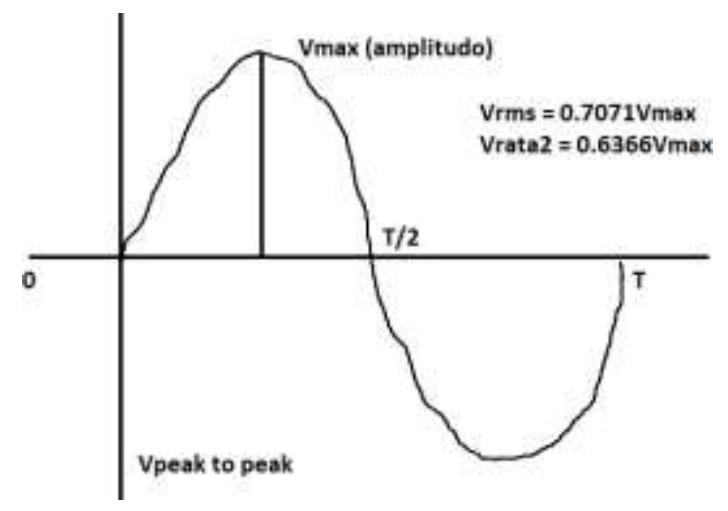

Gambar 2. 2 Gelombang Sinusoidal Tegangan

b. Induvidual Harmonic Distortion

Individual Harmonic Distortion (IHD) adalah perbandingan antara nilai RMS dari fundamentalnya, Misal nilai RMS dari harmonisa ketujuhnya adalah 10 A dan harmonisa kesembilannya adalah $25 \mathrm{~A}$, sedangkan nilai rms dari harmonisa fundamentalnya adalah $100 \mathrm{~A}$, maka

$$
\begin{gathered}
I H D_{7}=\frac{10}{100}=0.1 \%(\text { IHD ketujuh }) \\
I H D_{9}=\frac{25}{100}=0.25 \%(\text { IHD kesembilan })
\end{gathered}
$$

c. Total Harmonic Distortion
Total Harmonic Distortion (THD) adalah perbandingan antara nilai rms dari seluruh komponen harmonisa terhadap nilai rms dari nilai fundamentalnya biasanya dinyatakan dalam persen (\%). Nilai dari THD ini digunakan untuk mengukur besarnya penyimpangan dari bentuk gelombang periodik yang mengandung harmonisa dari gelombang sinusiodal murninya (S. Key, 1996). Untuk gelombang sinusiodal sempurna nilai dari THD adalah bernilai $0 \%$. Untuk mencari nilai THD untuk tegangan dan arus dapat menggunkan rumus sebagai berikut :

$\begin{aligned} I_{T H D} & =\frac{\sqrt{\sum_{n=2}^{\infty} I_{n^{2}}}}{I_{1}} \\ V_{T H D} & =\frac{\sqrt{\sum_{n=2}^{\infty} V_{n^{2}}}}{V_{1}}\end{aligned}$

Keterangan:

$\mathrm{V}_{\mathrm{n}}=$ Nilai Tegangan Harmonisa (Volt)

$\mathrm{V}_{1}=$ Nilai Tegangan Fundamental (Volt)

$\mathrm{I}_{\mathrm{n}}=$ Nilai Arus Harmonisa (Ampere)

$\mathrm{I}_{1}=$ Nilai Arus Fundamental (Ampere)

$\mathrm{n}=$ Orde Harmonisa

\section{Standar Harmonisa}

Standar Harmonisa adalah berdasarkan IEEE 519 - 1992. Ada dua kriteria yang digunakan untuk mengevalusai distorsi harmonisa, yang pertama adalah batas harmonisa untuk arus (ITHD) dan yang kedua adalah batasan untuk tegangan (V THD). Presentasi (\%) ITHD adalah presentase jumlah total arus yang terdistorsi oleh harmonisa terhadap frekuensi fundamentalnya. Batasan untuk harmonisa arus (ITHD) ditentukan oleh perbandingan Isc / IL. Isc adalah arus hubung singkat yang ada pada PCC (Point of Common Coupling), sedangkan IL adalah arus beban fundamental nominal. Sedangkan Presentasi (\%) batas untuk harmonisa tegangan (V THD), ditentukan dari besarnya tegangan sistem yang dipakai /terpasang.

Tabel 2. 1 Limit Distorsi Arus Harmonisa

\begin{tabular}{|c|c|c|c|c|c|c|}
\hline \multirow{3}{*}{$\mathrm{I}_{\mathrm{sc}} / \mathrm{I}_{\mathrm{L}}$} & \multicolumn{5}{|c|}{ HARMONIC ORDER } & \multirow{3}{*}{$\begin{array}{c}\text { Total } \\
\text { Harmonic } \\
\text { Distortion } \\
\text { (THD \%) }\end{array}$} \\
\hline & $<11$ & $\begin{array}{c}11 \leq \\
\mathrm{h}< \\
17\end{array}$ & $\begin{array}{l}17 \leq \\
h< \\
23\end{array}$ & $\begin{array}{c}23 \leq \\
h< \\
35\end{array}$ & $\begin{array}{c}35 \leq \\
\mathrm{h}\end{array}$ & \\
\hline & \multicolumn{5}{|c|}{ Individual Harmonic Distortion (IHD\%) } & \\
\hline$<20$ & 4.0 & 2.0 & 1.5 & 0.6 & 0.3 & 5 \\
\hline $20-50$ & 7.0 & 3.5 & 2.5 & 1.0 & 0.5 & 8 \\
\hline $50-100$ & 10.0 & 4.5 & 4.0 & 1.5 & 0.7 & 12 \\
\hline $\begin{array}{l}100- \\
1000\end{array}$ & 12.0 & 5.5 & 5.0 & 2.0 & 1.0 & 15 \\
\hline$>1000$ & 15.0 & 7.0 & 6.0 & 2.5 & 1.4 & 20 \\
\hline
\end{tabular}

ARUSMAKSIMUM DISTORSI HARMONISA DALAM SATUAN \%

Tabel 2. 2 Limit Distorsi Tegangan Harmonisa

\begin{tabular}{cccc} 
& \multicolumn{3}{c}{ Sistem Tegangan } \\
\cline { 2 - 4 } $\begin{array}{c}\text { Distorsi Maksimal } \\
\text { (\%) }\end{array}$ & $\mathrm{V} \leq 69$ & $\begin{array}{c}69<\mathrm{V}< \\
138\end{array}$ & $\begin{array}{c}\mathrm{V}>138 \\
\mathrm{kV}\end{array}$ \\
Individual & 3.0 & 1.5 & 1.0
\end{tabular}


Harmonisa

\section{MATODE PENELITIAN}

Pengambilan data yang dilakukan diambil dari gedung perkantoran yang berlokasi di Sudirman Central Business District, Jakarta Selatan. Ada 3 buah transformator distribusi yang digunakan untuk pengumpulan data serta arus dan tegangan THD (Total Harmonic Distortion) dari setiap fasa R,S, dan T. Kemudian, pada data pengukurannya diambil selama dua hari yakni, pada hari senin ketika hari kerja dan hari minggu ketika hari libur.

Peralatan pengukuran yang digunakan dalam pengambilan data ini ialah Power Analyzer bermerk Hioki dengan seri PQ3100. Alat ini mampu untuk mengukur berbagai komponen listrik seperti tegangan (V), arus (I), frekuensi (f), daya kompleks $(\mathrm{S})$, daya nyata $(\mathrm{P})$, daya reaktif $(\mathrm{Q})$, energi, dan faktor daya (PF). Selain itu, alat ini juga mampu mengukur komponen harmonisa arus dan tegangan sampai dengan orde ke-50. Alat ini memiliki input 4 terminal tegangan (3 tegangan fasa dan 1 netral) dan 4 terminal arus sehingga alat ini mampu mengukur sistem dari 1 phase-2 wire sampai 3 phase- 4 wire. Dilengkapi dengan PC card sebagai memori penyimpanan data pengukuran, sehingga alat ini mampu menyimpan data pengukuran secara otomatis. Data hasil pengukuran dapat dengan mudah ditransfer dari PC card ke komputer melalui universal card reader. Dengan bantuan program yang dimilikinya, hasil pengukuran dapat diamati dan dianalisis melalui komputer. Program yang digunakan adalah 9625 Power Measurement Support Software. Dari program ini kita bisa menyajikan data hasil pengukuran berupa ringkasan, grafik gelombang, dan spektrum untuk lebih memudahkan analisa. Kemudian, untuk mengukur suhu pada transformator digunakan termometer infrared digital, KW06-304 bermerk Krisbow yang dapat mengukur dari suhu $-50^{\circ} \mathrm{C}$ sampai $750^{\circ} \mathrm{C}$. Suhu yang diukur merupakan suhu pada saat transformator mengalami beban penuh.

\section{HASIL DAN PEMBAHASAN}

Spesifikasi transformator distribusi yang digunakan pada penelitian ini adalah sebagai berikut.

Tabel 3. 1 Spesifikasi Transformator Distribusi

\begin{tabular}{lc}
\hline \multicolumn{1}{c}{ Spesifikasi } & Keterangan \\
\hline Merk & CENTRADO \\
Arus Beban Nol & $1.6 \%$ \\
Impedansi $(\mathrm{Z})$ & $6 \%$ \\
Daya Semu $(\mathrm{S})$ & $1600 \mathrm{kVA}$
\end{tabular}

Tegangan Primer (VP)

$20 \mathrm{kV}$

Tegangan Sekunder (VS)

$400 \mathrm{~V}$

Arus Primer (IP)

Arus Sekunder (IS)

$46 \mathrm{~A}$

$2300 \mathrm{~A}$

Fasa

Frekuensi

$50 \mathrm{~Hz}$

Berat

$3800 \mathrm{Kg}$

Volume Oil

920 Liter

Sistem Pendingin

Tipe

ONAN

Tingkat Suara Bising

Indoor/Outdoor

Highest HV LV

$65 \mathrm{DB}$

20/0.4 KV

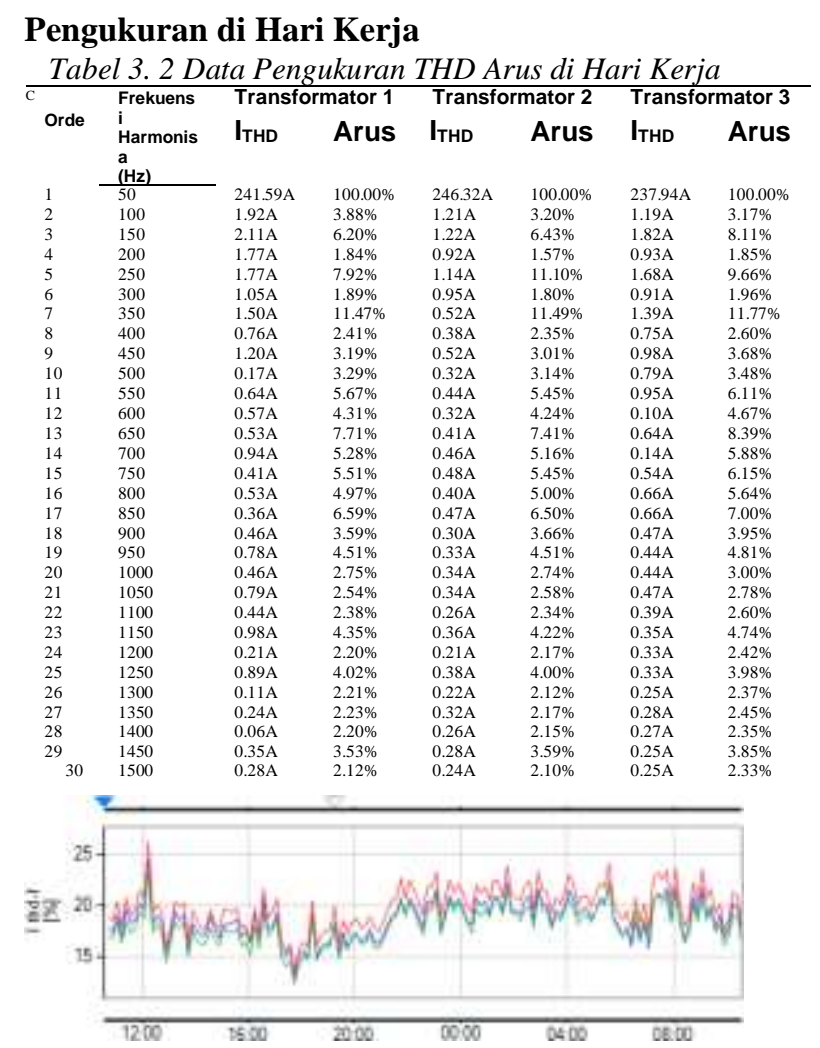

Gambar 3. 1 Grafik Tren THD-F Arus Tiap Orde di HarKerja

Pada grafik THD-F arus di hari kerja terlihat bahwa grafik sangat fluktuatif terhadap waktu. Hal ini disebabkan karena beban non linier yang digunakan pada hari kerja sangatlah banyak. Sehingga, THD-F yang dihasilkan pada transformasi distribusi juga berbanding lurus dengan beban non linier yang aktif pada saat itu.

Tabel 3. 3 Data Pengukuran THD Tegangan di Hari Kerja

\begin{tabular}{|c|c|c|c|c|c|c|c|}
\hline \multirow{2}{*}{$\begin{array}{l}\text { Or } \\
\text { de }\end{array}$} & \multirow{2}{*}{$\begin{array}{l}\text { Freku } \\
\text { e nsi } \\
\text { Harm } \\
\text { o nisa } \\
\text { (Hz) }\end{array}$} & \multicolumn{2}{|c|}{ Transformator 1} & \multicolumn{2}{|c|}{ Transformator 2} & \multicolumn{2}{|c|}{ Transformator 3} \\
\hline & & $V_{\text {THD }}$ & Volt & $\mathrm{V}_{\mathrm{THD}}$ & Volt & $\mathrm{V}_{\mathrm{THD}}$ & Volt \\
\hline 1 & 50 & $\begin{array}{l}100.0 \\
0 \%\end{array}$ & $\begin{array}{l}1552.2 \\
1 \mathrm{~V}\end{array}$ & $\begin{array}{l}100.0 \\
0 \%\end{array}$ & $\begin{array}{l}1553.5 \\
3 V\end{array}$ & $\begin{array}{l}100.0 \\
0 \%\end{array}$ & $\begin{array}{l}1552.3 \\
9 \mathrm{~V}\end{array}$ \\
\hline 2 & 100 & $0.10 \%$ & $0.24 \mathrm{~V}$ & $0.13 \%$ & $0.31 \mathrm{~V}$ & $0.12 \%$ & $0.28 \mathrm{~V}$ \\
\hline
\end{tabular}




\begin{tabular}{llllllll}
3 & 150 & $1.46 \%$ & $1.09 \mathrm{~V}$ & $1.53 \%$ & $0.95 \mathrm{~V}$ & $1.41 \%$ & $1.02 \mathrm{~V}$ \\
4 & 200 & $0.08 \%$ & $0.19 \mathrm{~V}$ & $0.09 \%$ & $0.21 \mathrm{~V}$ & $0.07 \%$ & $0.15 \mathrm{~V}$ \\
5 & 250 & $1.79 \%$ & $0.85 \mathrm{~V}$ & $1.76 \%$ & $0.62 \mathrm{~V}$ & $1.75 \%$ & $0.79 \mathrm{~V}$ \\
6 & 300 & $0.12 \%$ & $0.27 \mathrm{~V}$ & $0.12 \%$ & $0.27 \mathrm{~V}$ & $0.10 \%$ & $0.23 \mathrm{~V}$ \\
7 & 350 & $1.29 \%$ & $0.54 \mathrm{~V}$ & $0.99 \%$ & $0.44 \mathrm{~V}$ & $1.28 \%$ & $0.45 \mathrm{~V}$ \\
8 & 400 & $0.18 \%$ & $0.41 \mathrm{~V}$ & $0.18 \%$ & $0.42 \mathrm{~V}$ & $0.16 \%$ & $0.36 \mathrm{~V}$ \\
9 & 450 & $0.96 \%$ & $0.51 \mathrm{~V}$ & $1.02 \%$ & $0.45 \mathrm{~V}$ & $0.79 \%$ & $0.48 \mathrm{~V}$ \\
10 & 500 & $0.27 \%$ & $0.60 \mathrm{~V}$ & $0.27 \%$ & $0.62 \mathrm{~V}$ & $0.22 \%$ & $0.50 \mathrm{~V}$ \\
11 & 550 & $0.87 \%$ & $0.50 \mathrm{~V}$ & $0.87 \%$ & $0.40 \mathrm{~V}$ & $0.81 \%$ & $0.47 \mathrm{~V}$ \\
12 & 600 & $0.36 \%$ & $0.52 \mathrm{~V}$ & $0.37 \%$ & $0.33 \mathrm{~V}$ & $0.29 \%$ & $0.47 \mathrm{~V}$ \\
13 & 650 & $1.03 \%$ & $0.33 \mathrm{~V}$ & $1.07 \%$ & $0.32 \mathrm{~V}$ & $1.04 \%$ & $0.33 \mathrm{~V}$ \\
14 & 700 & $0.43 \%$ & $0.37 \mathrm{~V}$ & $0.43 \%$ & $0.38 \mathrm{~V}$ & $0.34 \%$ & $0.37 \mathrm{~V}$ \\
15 & 750 & $0.60 \%$ & $0.36 \mathrm{~V}$ & $0.54 \%$ & $0.21 \mathrm{~V}$ & $0.50 \%$ & $0.24 \mathrm{~V}$ \\
16 & 800 & $0.45 \%$ & $0.32 \mathrm{~V}$ & $0.44 \%$ & $0.24 \mathrm{~V}$ & $0.37 \%$ & $0.28 \mathrm{~V}$ \\
17 & 850 & $0.92 \%$ & $0.29 \mathrm{~V}$ & $0.81 \%$ & $0.33 \mathrm{~V}$ & $0.85 \%$ & $0.22 \mathrm{~V}$ \\
18 & 900 & $0.37 \%$ & $0.26 \mathrm{~V}$ & $0.37 \%$ & $0.33 \mathrm{~V}$ & $0.31 \%$ & $0.31 \mathrm{~V}$ \\
19 & 950 & $0.69 \%$ & $0.26 \mathrm{~V}$ & $0.73 \%$ & $0.15 \mathrm{~V}$ & $0.72 \%$ & $0.12 \mathrm{~V}$ \\
20 & 1000 & $0.32 \%$ & $0.23 \mathrm{~V}$ & $0.31 \%$ & $0.20 \mathrm{~V}$ & $0.27 \%$ & $0.11 \mathrm{~V}$ \\
21 & 1050 & $0.36 \%$ & $0.13 \mathrm{~V}$ & $0.34 \%$ & $0.19 \mathrm{~V}$ & $0.32 \%$ & $0.14 \mathrm{~V}$ \\
22 & 1100 & $0.30 \%$ & $0.18 \mathrm{~V}$ & $0.29 \%$ & $0.16 \mathrm{~V}$ & $0.25 \%$ & $0.17 \mathrm{~V}$ \\
23 & 1150 & $0.77 \%$ & $0.15 \mathrm{~V}$ & $0.72 \%$ & $0.16 \mathrm{~V}$ & $0.63 \%$ & $0.23 \mathrm{~V}$ \\
24 & 1200 & $0.30 \%$ & $0.18 \mathrm{~V}$ & $0.29 \%$ & $0.11 \mathrm{~V}$ & $0.24 \%$ & $0.15 \mathrm{~V}$ \\
25 & 1250 & $0.67 \%$ & $0.15 \mathrm{~V}$ & $0.66 \%$ & $0.11 \mathrm{~V}$ & $0.58 \%$ & $0.11 \mathrm{~V}$ \\
26 & 1300 & $0.29 \%$ & $0.16 \mathrm{~V}$ & $0.29 \%$ & $0.09 \mathrm{~V}$ & $0.23 \%$ & $0.11 \mathrm{~V}$ \\
27 & 1350 & $0.34 \%$ & $0.17 \mathrm{~V}$ & $0.37 \%$ & $0.16 \mathrm{~V}$ & $0.34 \%$ & $0.19 \mathrm{~V}$ \\
28 & 1400 & $0.29 \%$ & $0.25 \mathrm{~V}$ & $0.29 \%$ & $0.09 \mathrm{~V}$ & $0.23 \%$ & $0.21 \mathrm{~V}$ \\
29 & 1450 & $0.55 \%$ & $0.16 \mathrm{~V}$ & $0.56 \%$ & $0.11 \mathrm{~V}$ & $0.50 \%$ & $0.14 \mathrm{~V}$ \\
30 & 1500 & $0.28 \%$ & $0.14 \mathrm{~V}$ & $0.28 \%$ & $0.08 \mathrm{~V}$ & $0.22 \%$ & $0.11 \mathrm{~V}$ \\
\hline & & & & & & &
\end{tabular}

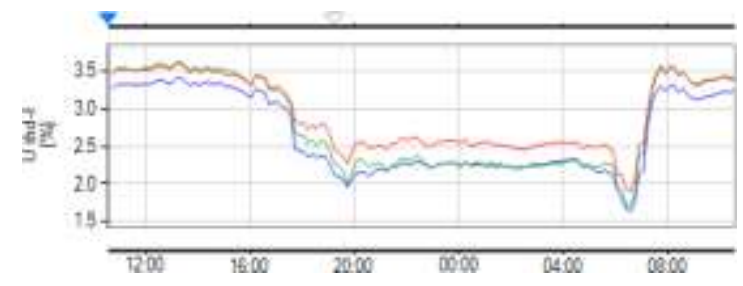

\section{Gambar 3. 2 Grafik Tren THD Tegangan Tiap Orde di Hari Kerja}

Pada grafik THD-F tegangan di hari kerja terlihat bahwa grafik dari pukul 12:00 sampai dengan 20:00 dan pukul 06:00 sampai dengan 08:00 mempunyai THD yang cukup besar. Namun, pada saat pukul 20:00 sampai dengan 06:00 grafik terlihat lebih stabil. Hal ini disebabkan karena ketika mengalami osilasi beban non linier pada gedung perkantoran banyak yang aktif sedangkan ketika tidak mengalami osilasi beban non linier kebanyakan tidak aktif.

Tabel 3. 4 Data Pengukuran Transformator Pada Hari

\begin{tabular}{llllllll}
\multicolumn{7}{c}{ Kerja } \\
\hline Trafo & $\begin{array}{l}\mathrm{F} \\
(\mathrm{Hz})\end{array}$ & $\begin{array}{l}\mathrm{P} \\
(\mathrm{KW})\end{array}$ & $\begin{array}{l}\mathrm{Q} \\
\text { (VAR) }\end{array}$ & $\begin{array}{l}\text { S } \\
(\mathrm{VA})\end{array}$ & $\mathrm{C}$ & ITHD & VTHD \\
\hline 1 & 50 & 124.24 & 378.5 & 238.68 & 62.8 & $26.29 \%$ & $4.61 \%$ \\
2 & 50 & 82.75 & 178.6 & 126.52 & 43.4 & $14.36 \%$ & $4.24 \%$ \\
3 & 50 & 123.87 & 323.89 & 210.12 & 59.3 & $24.42 \%$ & $4.43 \%$
\end{tabular}

\section{Pengukuran di Hari Libur}

Tabel 3. 5 Data Pengukuran THD Arus di Hari Libur

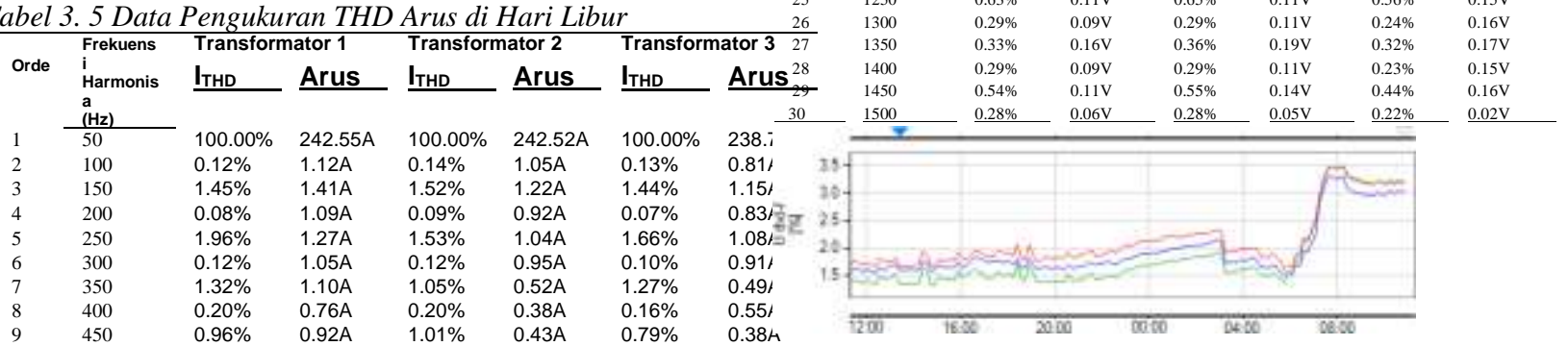

\begin{tabular}{llllllll}
10 & 500 & $0.29 \%$ & $0.67 \mathrm{~A}$ & $0.29 \%$ & $0.32 \mathrm{~A}$ & $0.24 \%$ & $0.59 \mathrm{~A}$ \\
11 & 550 & $0.83 \%$ & $0.44 \mathrm{~A}$ & $0.88 \%$ & $0.32 \mathrm{~A}$ & $0.76 \%$ & $0.35 \mathrm{~A}$ \\
12 & 600 & $0.37 \%$ & $0.47 \mathrm{~A}$ & $0.38 \%$ & $0.32 \mathrm{~A}$ & $0.31 \%$ & $0.30 \mathrm{~A}$ \\
13 & 650 & $1.05 \%$ & $0.43 \mathrm{~A}$ & $1.05 \%$ & $0.41 \mathrm{~A}$ & $1.06 \%$ & $0.34 \mathrm{~A}$ \\
14 & 700 & $0.43 \%$ & $0.44 \mathrm{~A}$ & $0.43 \%$ & $0.36 \mathrm{~A}$ & $0.35 \%$ & $0.14 \mathrm{~A}$ \\
15 & 750 & $0.60 \%$ & $0.41 \mathrm{~A}$ & $0.52 \%$ & $0.38 \mathrm{~A}$ & $0.51 \%$ & $0.22 \mathrm{~A}$ \\
16 & 800 & $0.42 \%$ & $0.43 \mathrm{~A}$ & $0.43 \%$ & $0.40 \mathrm{~A}$ & $0.34 \%$ & $0.36 \mathrm{~A}$ \\
17 & 850 & $0.90 \%$ & $0.36 \mathrm{~A}$ & $0.79 \%$ & $0.37 \mathrm{~A}$ & $0.85 \%$ & $0.23 \mathrm{~A}$ \\
18 & 900 & $0.36 \%$ & $0.36 \mathrm{~A}$ & $0.36 \%$ & $0.30 \mathrm{~A}$ & $0.30 \%$ & $0.37 \mathrm{~A}$ \\
19 & 950 & $0.68 \%$ & $0.38 \mathrm{~A}$ & $0.74 \%$ & $0.33 \mathrm{~A}$ & $0.71 \%$ & $0.24 \mathrm{~A}$ \\
20 & 1000 & $0.31 \%$ & $0.46 \mathrm{~A}$ & $0.30 \%$ & $0.34 \mathrm{~A}$ & $0.26 \%$ & $0.25 \mathrm{~A}$ \\
21 & 1050 & $0.35 \%$ & $0.49 \mathrm{~A}$ & $0.32 \%$ & $0.34 \mathrm{~A}$ & $0.29 \%$ & $0.27 \mathrm{~A}$ \\
22 & 1100 & $0.29 \%$ & $0.44 \mathrm{~A}$ & $0.29 \%$ & $0.26 \mathrm{~A}$ & $0.25 \%$ & $0.29 \mathrm{~A}$ \\
23 & 1150 & $0.74 \%$ & $0.48 \mathrm{~A}$ & $0.69 \%$ & $0.36 \mathrm{~A}$ & $0.64 \%$ & $0.15 \mathrm{~A}$ \\
24 & 1200 & $0.30 \%$ & $0.21 \mathrm{~A}$ & $0.29 \%$ & $0.21 \mathrm{~A}$ & $0.24 \%$ & $0.13 \mathrm{~A}$ \\
25 & 1250 & $0.63 \%$ & $0.39 \mathrm{~A}$ & $0.65 \%$ & $0.18 \mathrm{~A}$ & $0.56 \%$ & $0.19 \mathrm{~A}$ \\
26 & 1300 & $0.29 \%$ & $0.11 \mathrm{~A}$ & $0.29 \%$ & $0.22 \mathrm{~A}$ & $0.24 \%$ & $0.15 \mathrm{~A}$ \\
27 & 1350 & $0.33 \%$ & $0.24 \mathrm{~A}$ & $0.36 \%$ & $0.24 \mathrm{~A}$ & $0.32 \%$ & $0.14 \mathrm{~A}$ \\
28 & 1400 & $0.29 \%$ & $0.26 \mathrm{~A}$ & $0.29 \%$ & $0.16 \mathrm{~A}$ & $0.23 \%$ & $0.13 \mathrm{~A}$ \\
29 & 1450 & $0.54 \%$ & $0.24 \mathrm{~A}$ & $0.55 \%$ & $0.18 \mathrm{~A}$ & $0.44 \%$ & $0.08 \mathrm{~A}$ \\
30 & 1500 & $\underline{0.28 \%}$ & $\underline{0.18 \mathrm{~A}}$ & $\underline{0.28 \%}$ & $\underline{0.12 \mathrm{~A}}$ & $\underline{0.22 \%}$ & $\underline{0.09 \mathrm{~A}}$ \\
\hline
\end{tabular}

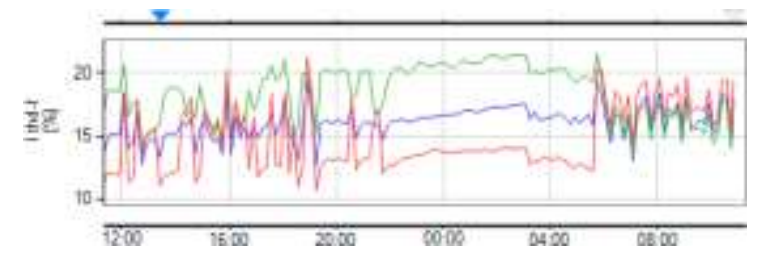

Gambar 3. 3 Grafik Tren THD Arus Tiap Orde di Hari Libur

Pada grafik THD-F arus di hari libur terlihat bahwa grafik dari pukul 12:00 sampai dengan 22:00 dan pukul 06:00 sampai dengan 10:00 cukup mengalami osilasi. Namun, pada saat pukul 22:00 sampai dengan 06:00 grafik terlihat lebih stabil. Hal ini disebabkan karena ketika mengalami osilasi beban non linier pada gedung perkantoran banyak yang aktif sedangkan ketika tidak mengalami osilasi beban non linier kebanyakan tidak aktif.

Tabel 3. 6 Data Pengukuran THD Tegangan di Hari Libur

\begin{tabular}{|c|c|c|c|c|c|c|c|}
\hline \multirow{2}{*}{ Orde } & \multirow{2}{*}{$\begin{array}{l}\text { Frekuens } \\
\text { i } \\
\text { Harmonis } \\
\text { a }(\mathrm{Hz})\end{array}$} & \multicolumn{2}{|c|}{ Transformator 1} & \multicolumn{2}{|c|}{ Transformator 2} & \multicolumn{2}{|c|}{ Transformator 3} \\
\hline & & VTHD & Volt & VTHD & Volt & VTHD & Volt \\
\hline \multirow[t]{2}{*}{1} & \multirow{2}{*}{50} & 100.00 & 1442.91 & 100.00 & 1443.67 & 100.00 & 1442.75 \\
\hline & & $\%$ & & $\%$ & & & \\
\hline \multirow{2}{*}{2} & 100 & $0.12 \%$ & $0.26 \mathrm{~V}$ & $0.14 \%$ & $0.28 \mathrm{~V}$ & $0.13 \%$ & $0.24 \mathrm{~V}$ \\
\hline & 150 & $1.45 \%$ & $0.55 \mathrm{~V}$ & $1.52 \%$ & $0.42 \mathrm{~V}$ & $1.44 \%$ & $0.39 \mathrm{~V}$ \\
\hline $\begin{array}{l}3 \\
4\end{array}$ & 200 & $0.08 \%$ & $0.21 \mathrm{~V}$ & $0.09 \%$ & $0.15 \mathrm{~V}$ & $0.07 \%$ & $0.19 \mathrm{~V}$ \\
\hline 5 & 250 & $1.96 \%$ & 0.52 & $1.53 \%$ & $0.39 \mathrm{~V}$ & $1.66 \%$ & $0.35 \mathrm{~V}$ \\
\hline \multirow{2}{*}{$\begin{array}{l}6 \\
7\end{array}$} & 300 & $0.12 \%$ & $0.27 \mathrm{~V}$ & $0.12 \%$ & $0.23 \mathrm{~V}$ & $0.10 \%$ & $0.27 \mathrm{~V}$ \\
\hline & 350 & $1.32 \%$ & $0.39 \mathrm{~V}$ & $1.05 \%$ & $0.35 \mathrm{~V}$ & $1.27 \%$ & $0.24 \mathrm{~V}$ \\
\hline 8 & 400 & $0.20 \%$ & $0.35 \mathrm{~V}$ & $0.20 \%$ & $0.36 \mathrm{~V}$ & $0.16 \%$ & $0.31 \mathrm{~V}$ \\
\hline 9 & 450 & $0.96 \%$ & $0.35 \mathrm{~V}$ & $1.01 \%$ & $0.38 \mathrm{~V}$ & $0.79 \%$ & $0.21 \mathrm{~V}$ \\
\hline \multirow{2}{*}{10} & 500 & $0.29 \%$ & $0.42 \mathrm{~V}$ & $0.29 \%$ & $0.37 \mathrm{~V}$ & $0.24 \%$ & $0.20 \mathrm{~V}$ \\
\hline & 550 & $0.83 \%$ & $0.45 \mathrm{~V}$ & $0.88 \%$ & $0.32 \mathrm{~V}$ & $0.76 \%$ & $0.20 \mathrm{~V}$ \\
\hline $\begin{array}{l}11 \\
12\end{array}$ & 600 & $0.37 \%$ & $0.38 \mathrm{~V}$ & $0.38 \%$ & $0.27 \mathrm{~V}$ & $0.31 \%$ & $0.22 \mathrm{~V}$ \\
\hline 13 & 650 & $1.05 \%$ & $0.37 \mathrm{~V}$ & $1.05 \%$ & $0.33 \mathrm{~V}$ & $1.06 \%$ & $0.23 \mathrm{~V}$ \\
\hline \multirow{2}{*}{$\begin{array}{l}14 \\
15\end{array}$} & 700 & $0.43 \%$ & $0.28 \mathrm{~V}$ & $0.43 \%$ & $0.37 \mathrm{~V}$ & $0.35 \%$ & $0.27 \mathrm{~V}$ \\
\hline & 750 & $0.60 \%$ & $0.24 \mathrm{~V}$ & $0.52 \%$ & $0.24 \mathrm{~V}$ & $0.51 \%$ & $0.26 \mathrm{~V}$ \\
\hline 16 & 800 & $0.42 \%$ & $0.23 \mathrm{~V}$ & $0.43 \%$ & $0.28 \mathrm{~V}$ & $0.34 \%$ & $0.22 \mathrm{~V}$ \\
\hline 17 & 850 & $0.90 \%$ & $0.25 \mathrm{~V}$ & $0.79 \%$ & $0.22 \mathrm{~V}$ & $0.85 \%$ & $0.29 \mathrm{~V}$ \\
\hline \multirow{2}{*}{$\begin{array}{l}18 \\
19\end{array}$} & 900 & $0.36 \%$ & $0.21 \mathrm{~V}$ & $0.36 \%$ & $0.31 \mathrm{~V}$ & $0.30 \%$ & $0.26 \mathrm{~V}$ \\
\hline & 950 & $0.68 \%$ & $0.15 \mathrm{~V}$ & $0.74 \%$ & $0.12 \mathrm{~V}$ & $0.71 \%$ & $0.26 \mathrm{~V}$ \\
\hline 20 & 1000 & $0.31 \%$ & $0.10 \mathrm{~V}$ & $0.30 \%$ & $0.11 \mathrm{~V}$ & $0.26 \%$ & $0.23 \mathrm{~V}$ \\
\hline 21 & 1050 & $0.35 \%$ & $0.19 \mathrm{~V}$ & $0.32 \%$ & $0.14 \mathrm{~V}$ & $0.29 \%$ & $0.13 \mathrm{~V}$ \\
\hline 22 & 1100 & $0.29 \%$ & $0.12 \mathrm{~V}$ & $0.29 \%$ & $0.17 \mathrm{~V}$ & $0.25 \%$ & $0.18 \mathrm{~V}$ \\
\hline 23 & 1150 & $0.74 \%$ & $0.12 \mathrm{~V}$ & $0.69 \%$ & $0.23 \mathrm{~V}$ & $0.64 \%$ & $0.15 \mathrm{~V}$ \\
\hline \multirow{2}{*}{24} & 1200 & $0.30 \%$ & $0.08 \mathrm{~V}$ & $0.29 \%$ & $0.15 \mathrm{~V}$ & $0.24 \%$ & $0.18 \mathrm{~V}$ \\
\hline & 1250 & $0.63 \%$ & $0.11 \mathrm{~V}$ & $0.65 \%$ & $0.11 \mathrm{~V}$ & $0.56 \%$ & $0.15 \mathrm{~V}$ \\
\hline $\begin{array}{l}25 \\
26 \\
\end{array}$ & 1300 & $0.29 \%$ & $0.09 \mathrm{~V}$ & $0.29 \%$ & $0.11 \mathrm{~V}$ & $0.24 \%$ & $0.16 \mathrm{~V}$ \\
\hline 27 & 1350 & $0.33 \%$ & $0.16 \mathrm{~V}$ & $0.36 \%$ & $0.19 \mathrm{~V}$ & $0.32 \%$ & $0.17 \mathrm{~V}$ \\
\hline $3^{28}$ & 1400 & $0.29 \%$ & $0.09 \mathrm{~V}$ & $0.29 \%$ & $0.11 \mathrm{~V}$ & $0.23 \%$ & $0.15 \mathrm{~V}$ \\
\hline & 1450 & $0.54 \%$ & $0.11 \mathrm{~V}$ & $0.55 \%$ & $0.14 \mathrm{~V}$ & $0.44 \%$ & $0.16 \mathrm{~V}$ \\
\hline 30 & 1500 & $0.28 \%$ & $\underline{0.06 \mathrm{~V}}$ & $0.28 \%$ & $\underline{0.05 \mathrm{~V}}$ & $\underline{0.22 \%}$ & $0.02 \mathrm{~V}$ \\
\hline & & & & & & & \\
\hline & & & & & & & \\
\hline & & & & & & & \\
\hline & & & & & & & \\
\hline & & & & & & & \\
\hline & & & & & & & \\
\hline
\end{tabular}


Gambar 3. 4 Grafik Tren THD Tegangan Tiap Orde di Hari Kerja

Pada grafik THD-F arus di hari libur terlihat bahwa grafik cukup stabil. Namun, pada pukul 06:00 keatas THD-F arus mulai memuncak. Hal ini disebabkan karena pada pukul 06:00 kebawah beban non linier yang digunakan sedikit. Sedangkan pada pukul 06:00 keatas beban non linier mulai aktif kembali.

Tabel 3. 7 Data Pengukuran Transformator Pada Hari Libur

\begin{tabular}{llllllll}
\hline Trafo & $\begin{array}{l}\text { F } \\
(\mathrm{Hz})\end{array}$ & $\begin{array}{l}\mathrm{P} \\
(\mathrm{KW})\end{array}$ & $\begin{array}{l}\mathrm{Q} \\
(\mathrm{V} A R)\end{array}$ & $\begin{array}{l}\mathrm{S} \\
(\mathrm{VA})\end{array}$ & $\mathrm{C}$ & ITHD & VTHD \\
\hline $\mathbf{1}$ & $\mathbf{5 0}$ & $\mathbf{1 2 4 . 2 4}$ & $\mathbf{3 7 8 . 5}$ & $\mathbf{2 3 8 . 6 8}$ & $\mathbf{5 1 . 2}$ & $\mathbf{1 8 . 3 2 \%}$ & $\mathbf{3 . 5 0 \%}$ \\
$\mathbf{2}$ & $\mathbf{5 0}$ & $\mathbf{8 2 . 7 5}$ & $\mathbf{1 7 8 . 6}$ & $\mathbf{1 2 6 . 5 2}$ & $\mathbf{3 8 . 3}$ & $\mathbf{1 3 . 5 4 \%}$ & $\mathbf{3 . 4 9 \%}$ \\
$\mathbf{3}$ & $\mathbf{5 0}$ & $\mathbf{1 2 3 . 8 7}$ & $\mathbf{3 2 3 . 8 9}$ & $\mathbf{2 1 0 . 1 2}$ & $\mathbf{3 5 . 9}$ & $\mathbf{1 2 . 3 4 \%}$ & $\mathbf{3 . 3 2 \%}$ \\
\hline
\end{tabular}

Berdasarkan data diatas diketahui bahwa nilai arus THD ganjil relatif lebih besar dibandingkan THD genap. Melalui data-data pengukuran tersebut akan dilakukan perhitungan THD arus dan tegangan pada transformator 1,2, dan 3 di hari kerja dan hari libur yang nantinya akan dibandingkan dengan nilai pengukuran. Hasil pengukuran dan perhitungan dibandingkan yang kemudian akan dievaluasi berdasarkan standar harmonisa yang telah ditetapkan pada IEEE 5191992. Pengukuran dilakukan pada saat beban penuh agar dapat mengetahui efek harmonisa secara akurat pada transformator distribusi.

\section{Perhitungan di Hari Kerja}

a. Arus

$\mathrm{I}_{\mathrm{THD}}$ pada transformator 1:

$$
\begin{aligned}
I_{T H D} & =\frac{\sqrt{\sum_{n=2}^{\infty} I_{n^{2}}}}{I_{1}} \\
& =\sqrt{\frac{I_{3}^{2}+I_{5}^{2}+I_{7}^{2}+I_{9}^{2}+\cdots+I_{29}^{2}}{I_{1}}} \\
& =\sqrt{\frac{1.92^{2}+1.77^{2}+1.5^{2}+1.2^{2}+\cdots+0.35^{2}}{241.59}} \\
& =\sqrt{\frac{15.43}{241.59}}=0.25271=25.27 \%
\end{aligned}
$$

ISC/ IL pada Tranformator 1:

Diketahui:

$$
\begin{aligned}
\mathrm{I}_{\mathrm{L}} & =241.59 \mathrm{~A} \\
\mathrm{Z} & =6 \% \\
\mathrm{~V} & =0.4 \mathrm{kV} \\
\mathrm{S} & =1600 \mathrm{kVA} \\
I_{S C} & =\frac{k V A \times 100}{\% Z \times \sqrt{3} \times k V}
\end{aligned}
$$

$$
\begin{aligned}
& I_{S C}=\frac{1600 \times 100}{6 \times \sqrt{3} \times 0.4}=\frac{160000}{4}=40000 \\
& \frac{I_{S C}}{I_{L}}=\frac{40000}{241.59}=40000=165.56 \\
& \text { Jadi, standar yang digunakan pada }
\end{aligned}
$$
transformator 1 adalah THDi $15 \%$ seperti yang ditunjukan pada Tabel 2.2 karena hasil dari perhitungan Isc/IL berada pada range 100 1000. Kemudian, digunakan juga rumus yang sama pada transformator 2 dan 3 untuk mencari ITHD dan Isc / IL didapat Tabel sebagai berikut: Tabel 3. 8 Analisis THD Arus di Hari Kerja

\begin{tabular}{lcccc} 
Transformator & \multicolumn{3}{c}{ THD Arus (\%) } & Evaluasi \\
& Pengukuran & Perhitungan & Standar & \\
\hline Transformator 1 & 26.29 & 25.27 & 15 & $>$ Standar \\
Transformator 2 & 14.36 & 13.99 & 15 & < Standar \\
Transformator 3 & 24.42 & 22.32 & 15 & $>$ Standar \\
\hline
\end{tabular}

Hasil perhitungan dan pengukuran ITHD pada hari kerja menunjukan bahwa hasil yang relatif hampir sama atau perbedaannya tidak terlalu jauh. Artinya peralatan yang dipakai untuk melakukan pengukuran cukup presisi. Dari ketiga transformator untuk hasil pengukuran diperoleh ITHD berkisar antara $14.36 \%-26.29 \%$ sedangkan untuk hasil ITHD perhitungan berkisar antara $13.99 \%-25.27 \%$. Dari data ini memperlihatkan bahwa transformator 1 dan 3 mempunyai harmonisa melebihi standar baik secara pengukuran maupun perhitungan. Hal ini disebabkan beban non linier yang dipergunakan lebih banyak bila dibandingkan transformator 2 seperti komputer, lampu hemat energi, printer, komponen elektronika daya atau peralatan yang mempunyai kondisi saturasi yang bekerja pada setiap siklus gelombang dari sumber tegangan. Proses kerja ini akan menghasilkan gangguan atau distorsi gelombang arus yang tidak sinusiodal. jumlah beban non linier akan menghasilkan gelombang yang kemudian menirathillean harmonisa pada gelombang arus fundamental. Distorsi harmonisa yang besar ini menyebabkan pemanasan lebih pada belitan transformator distribusi dan akan meyebabkan kenaikan tempantur. Dengan demikian untuk transformator 3 gangguan harmonisa arus berpotensi besar dari keseluruhan transformator yang diamati. Dengan demikian transformator berpotensi terjadi gangguama hamionisa apabila penggunaan beban tidak linier bertambah. Dalam melakukan perhitungan. standar yang dipakai adalah standar dari IEEE 519-1992.

b. Tegangan

$\mathrm{V}_{\text {THD }}$ pada Transformator 1:

$V_{T H D}=\frac{\sqrt{\sum_{n=2}^{\infty} V_{n^{2}}}}{V_{1}}$ 


$$
\begin{aligned}
& =\sqrt{\frac{V_{3}^{2}+V_{5}^{2}+V_{7}^{2}+V_{9}^{2}+\cdots+V_{29}^{2}}{V_{1}}} \\
& =\sqrt{\frac{1.92^{2}+0.85^{2}+0.54^{2}+0.51^{2}+\cdots+0.16^{2}}{1552.21}} \\
& =0.04554=4.55 \%
\end{aligned}
$$

Tabel 3. 9 Analisis THD Tegangan di Hari Kerja

\begin{tabular}{lcccc}
\hline Transformator & \multicolumn{3}{c}{ THD Tegangan (\%) } & Evaluasi \\
& Pengukuran & Perhitungan & Standar & \\
\hline Transformator 1 & 4.61 & 4.55 & 5 & $<$ Standar \\
Transformator 2 & 4.24 & 3.79 & 5 & $<$ Standar \\
Transformator 3 & 4.43 & 4.16 & 5 & $<$ Standar \\
\hline
\end{tabular}

Dari Tabel 2.2 terlihat bahwa THD tegangan pada ketiga transformator masih dibawah standar IEEE 519-1992 sehingga hal iui menunjukan distorsi harmonisa tidak membahayakan untuk transformator. Persentasi VTHD pada pengukuran berkisar antara 4,24\% - 4.61\% dan untuk persentasi VTHD pada perhitungan berkisar antara $3.79 \%-4.55 \%$. Dari hasil persentasi dapat disimpulkan bahwa masih dibawah standar yang diijinkan yakni 5\%. Dan hasilnya cukup presisi karena perbedaan antara nilai pengukuran dan perhitungan tidak begitu jauh. Oleh karena itu, spektrum distorsi harmonisa tidak menunjukan masalah yang berarti atau berbahaya

\section{Perhitungan di Hari Libur}

a. Arus

$\mathrm{I}_{\mathrm{THD}}$ pada transformator 1:

$$
\begin{aligned}
& I_{T H D}=\frac{\sqrt{\sum_{n=2}^{\infty} I_{n^{2}}}}{I_{1}} \\
& =\sqrt{\frac{I_{3}^{2}+I_{5}^{2}+I_{7}^{2}+I_{9}^{2}+\cdots+I_{29}^{2}}{I_{1}}}
\end{aligned}
$$

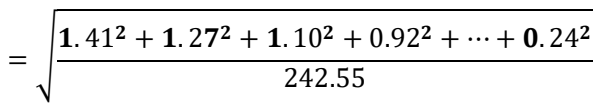

$$
\begin{aligned}
& =\sqrt{\frac{7.21}{242.55}}=0.1724=17.24 \%
\end{aligned}
$$

ISC/ IL pada Tranformator 1:

Diketahui:

$\mathrm{I}_{\mathrm{L}}=242.55 \mathrm{~A}$

$\mathrm{Z}=6 \%$

$\mathrm{V}=0.4 \mathrm{kV}$

$\mathrm{S}=1600 \mathrm{kVA}$

$I_{S C}=\frac{k V A \times 100}{\% Z \times \sqrt{3} \times k V}$
$I_{S C}=\frac{1600 \times 100}{6 \times \sqrt{3} \times 0.4}=\frac{160000}{4}=40000$

$\frac{I_{S C}}{I_{L}}=\frac{40000}{242.55}=40000=164.91$

Jadi, standar yang digunakan pada transformator 1 adalah THDI 15\% seperti yang ditunjukan pada Tabel 2.2 karena hasil dari perhitungan ISC/IL berada pada range $100-$ 1000. Kemudian, digunakan juga rumus yang sama pada transformator 2 dan 3 untuk mencari ITHD dan ISC / IL didapat Tabel sebagai berikut:

Tabel 3. 10 Analisis THD Arus di Hari Libur

\begin{tabular}{lcccc} 
Transformator & \multicolumn{3}{c}{ THD Arus (\%) } & \\
& Pengukuran & Perhitungan & Standar & \\
\hline Transformator 1 & 18.32 & 17.24 & 15 & $>$ Standar \\
Transformator 2 & 13.54 & 12.92 & 15 & $<$ Standar \\
Transformator 3 & 12.34 & 11.98 & 15 & $<$ Standar \\
\hline
\end{tabular}

Hasil perhitungan dan pengukuran ITHD pada hari libur menunjukan bahwa hasil yang relatif hampir sama atau perbedaannya tidak terlalu jauh. Artinya peralatan yang dipakai untuk melakukan pengukuran cukup presisi. Dari ketiga transformator untuk hasil pengukuran diperoleh ITHD berkisar antara $12.34 \%$ - $18.32 \%$ sedangkan untuk hasil ITHD perhitungan berkisar antara 11.98\% - 17.24\%. Dari data ini memperlihatkan bahwa hanya transformator 1 yang mempunyai harmonisa melebihi standar baik secara pengukuran maupun perhitungan. Berbeda dengan hari kerja, ITHD pada hari libur menurun cukup signifikan. Hal ini disebabkan karena beban non linier yang digunakan lebih sedikit daripada beban non linier yang digunakan pada hari kerja.

b. Tegangan

$\mathrm{V}_{\text {THD }}$ pada Transformator 1:

$$
\begin{aligned}
& V_{T H D}=\frac{\sqrt{\sum_{n=2}^{\infty} V_{n^{2}}}}{I_{1}} \\
& =\sqrt{\frac{V_{3}^{2}+V_{5}^{2}+V_{7}^{2}+V_{9}^{2}+\cdots+V_{29}^{2}}{V_{1}}} \\
& =\sqrt{\frac{0.55^{2}+0.52^{2}+0.39^{2}+0.35^{2}+\cdots+0.11^{2}}{1442.91}} \\
& =\mathbf{0 . 0 3 1 4 8}=3.14 \%
\end{aligned}
$$

Tabel 3. 11 Analisis THD Tegangan di Hari Libur

\begin{tabular}{lcccc}
\hline \multirow{2}{*}{ Transformator } & \multicolumn{3}{c}{ THD Tegangan (\%) } & Evaluasi \\
& Pengukuran & Perhitungan & Standar & \\
\hline Transformator 1 & 3.50 & 3.14 & 5 & $<$ Standar \\
Transformator 2 & 3.49 & 2.71 & 5 & $<$ Standar
\end{tabular}


Transformator 3 3.32 2.36

Dari Tabel 2.2 terlihat bahwa THD tegangan pada ketiga transformator masih dibawah standar IEEE 519-1992 sehingga hal iui menunjukan distorsi harmonisa tidak membahayakan untuk transformator. Persentasi VTHD pada pengukuran berkisar antara 3,32\% - $3.50 \%$ dan untuk persentasi VTHD pada perhitungan berkisar antara $2.36 \%-3.14 \%$. Dari hasil persentasi dapat disimpulkan bahwa masih dibawah standar yang diijinkan yakni 5\%. Dan hasilnya cukup presisi karena perbedaan antara nilai pengukuran dan perhitungan tidak begitu jauh. Oleh karena itu, spektrum distorsi harmonisa tidak menunjukan masalah yang berarti atau berbahaya.

\section{PENUTUP}

\section{Kesimpulan}

Dari uraian data dan hasil perhitungan analisis pengaruh harmonisa pada transformator distribusi, maka dapat disimpulkan:

1. Berdasarkan hasil pengukuran dan perhitungan di hari kerja, ITHD pada transformator 1 dan 3 berada diluar batas yang telah ditentukan pada IEEE 519-1992 yaitu sebesar $25.27 \%$ dan $22.32 \%$ (batas standar 15\%).

2. Berdasarkan hasil pengukuran dan perhitungan di hari libur, ITHD pada transformator 1 berada diluar batas yang telah ditentukan pada IEEE 519-1992 yaitu sebesar 17.24\% (batas standar $15 \%)$.

3. Berdasarkan hasil pengukuran dan perhitungan di hari kerja, VTHD pada masing-masing transformator berada dalam batas normal yaitu $4.55 \%, 3.79 \%$, dan $4.16 \%$ (batas standar 5\%).

4. Berdasarkan hasil pengukuran dan perhitungan di hari kerja, VTHD pada masing-masing transformator berada dalam batas normal yaitu $3.14 \%, 2.71 \%$, dan $2.36 \%$ (batas standar 5\%).

5. Perbandingan antara beban harmonisa di hari kerja dan hari libur mempunyai perbedaan yang cukup signifikan. Hal ini terjadi karena beban non linier yang aktif pada hari kerja lebih banyak daripada hari libur.

6. Semakin besar arus harmonisa yang terjadi (26.29\%), semakin tinggi pula suhu yang terukur $\left(62.8^{\circ} \mathrm{C}\right)$.

\section{REFERENSI}

Koswara, Indra Firmansyah. (2010). Analisis Pengaruh Harmonik Pada Transformator Daya di Industri Semen.

Dugan, Roger. (2004). Electrical Power System Quality, Second Edition, McGraw-Hill

Geduldt, Owen Christoper (2015). The Impact of Harmonic Distortion on Power Transformer Operating Near The Thermal Limit

Tobing, Cristof N.H. (2008). Pengaruh Harmonik Pada Transformator Distribusi

De Keulaer, Hans. (2008). Transformer derating, Leonardo Energy's Flagship Publication, Brussels, Belgiun

S. Key, Thomas. 1996. Cost and Benefit of Harmonic Current for Switch-Mode Power Supplies in Commercial Office Building, IEEE Transaction on Industries Application, Vol 32, No 5

J. Arrilaga, Bradley D.A., Bodger P.S., (2003) Power System Harmonics, New York : John Wiley \& Sons 